\title{
FAKTOR PENYEBAB AKTIVITAS PEMBALAKAN LIAR KAWASAN TAMAN HUTAN RAYA BUKIT BARISAN PROVINSI SUMATERA UTARA
}

(Factors Causing Illegal Logging Activities In The Bukit Barisan Grand Forest Park Area, North Sumatera Province)

\author{
Serlinta Bangun ${ }^{1}$, Ashabul Anhar ${ }^{1 *}$, Ryan Moulana ${ }^{1}$ \\ ${ }^{1}$ Program Studi Kehutanan PSDKU Unsyiah Gayo Lues \\ Universitas Syiah Kuala \\ *Corresponding author: ashabul.anhar@gmail.com
}

\begin{abstract}
Abstrak. Pembalakan liar adalah suatu kegiatan penebangan kayu yang dilakukan secara tidak sah tanpa ada izin otoritas setempat dan melanggar peraturan perundanng-undangan, yaitu berupa pencurian kayu didalam kawasan hutan Negara atau hutan Hak dan atau pemegang izin melakukan pembalakan lebih dari jatah yang telah ditetapkan dalam perizinan. Tujuan penelitian ini untuk mengetahui faktor-faktor aktivitas pembalakan liar di kawasan Taman Hutan Raya Bukit Barisan provinsi Sumatera Utara. Pengukuran faktorfaktor menurut responden dilaksanakan melalui wawancara menggunakan kuisioner dan observasi lapangan yang kemudian di deskripsikan. Adapun faktor yang tergolong tinggi terdapat pada faktor ekonomi.
\end{abstract}

Kata kunci: Pembalakan Liar.

Abstract. illegal logging is illegal logging and violates statutory regulations, namely in the form of theft of wood in State forest areas or private forests and / or permit holders logging more than the quota stipulated in the permit. The purpose of this study was to determine the factors of illegal logging activities in the Bukit Barisan Forest Park area, North Sumatera Province. The measurement of the factors according to the respondents was carried out by means of interviews using a questionnaire and field observations which were then described. The factors that are classified as high are economic factors.

Keywords: Illegal Logging. 


\section{PENDAHULUAN}

Taman Hutan Raya merupakan suatu kawasan pelestarian alam yang digunakan sebagai tujuan koleksi tumbuhan baik satwa yang alami atau buatan, jenis asli dan bukan asli, yang dapat dimanfaatkan bagi kepentingan penelitian, ilmu pengetahuan, pendidikan, menunjang budidaya, budaya, pariwisata dan rekreasi. Merujuk terminologi tersebut, menurut UUD No.5 Tahun 1990 tentang Konservasi Sumberdaya Alam Hayati dan Ekosistemnya, pada Pasal 1 Ayat 1 Point 15 maka dapat dipastikan salah satu upaya memelihara, melindungi dan melestarikan sumberdaya hutan dapat dilakukan melalui pengelolaan taman hutan raya yang dilakukan sesuai dengan aturan yang berlaku.

Permasalahan yang terjadi di sekitar kawasan Taman Hutan Raya Bukit Barisan terdiri dari faktor internal dan faktor eksternal. Faktor eksternal yang sangat meresahkan masyarakat adalah masalah pembalakan liar. Pembalakan liar adalah kegiatan penebangan, pengangkutan atau penjualan kayu yang tidak sah atau tidak memiliki izin otoritas setempat.

Berdasarkan hasil penelitian sebelumnya mengenai faktor pembalakan liar yang dilakukan di Taman Nasional Bukit Selatan Desa Tirom, Kecamatan Pematang Sawa, Kabupaten Tanggamus, menunjukkan bahwa faktor sosial ekonomi seperti pendapatan rendah, sedikitnya sumber penghidupan dan kurangnya kapasitas masyarakat dalam mengelola pertanian lahan sempit, merupakan faktor utama penyebab permasalahan hutan. Selain itu berdasarkan hasil analisis regresi diketahui bahwa tidak ada hubungan yang kuat antara tindakan pembalakan liar dengan pendapatan dan kepemilikan lahan pribadi, (Selly 2011).

Hasil penelitian lainnya mengenai dampak pembalakan liar di Desa Bulu Hadik, Kecamatan Teluk Dalam, Kabupaten Simeuleu, Aceh, menunjukkan bahwa penyebab kerusakan hutan yang terjadi umumnya disebabkan oleh perluasan perkebunan terutama untuk tanaman kelapa sawit. Dari 102 orang yang dijadikan responden 75,4\% melakukan kegiatan pembukaan lahan untuk dijadikan perkebunan kelapa sawit sedangkan 24,5\% lainnya tidak memiliki lahan, (Susilawati 2008).

Peningkatan peranan masyarakat menjadi salah satu aspek penting dalam pengelolaan kawasan hutan. (Sunoto, 1997) mengatakan bahwa peranan masyarakat dapat dilihat melalui keadaan sosial ekonomi, pemanfaatan kearifan lokal, perlindungan terhadap teknologi tradisional dan ramah lingkungan, serta peningkatan kepatuhan masyarakat terhadap peraturan perundang-undangan dan tata nilai masyarakat lokal, yang berwawasan lingkungan hidup. Hal ini menunjukkan pentingnya peranan masyarakat dalam mengelola dan melindungi kawasan hutan. Namun, pada sisi lain masyarakat juga dapat berperan sebaliknya, sebagai pelaku pembalakan liar. Keterbatasan lahan yang dimiliki dan tingginya tingkat kebutuhan, menyebabkan masyarakat memperluas areal pertanian.Sayangnya pembalakan liar yang dilakukan tanpa memikirkan aspek kelestarian, 
hanya memikirkan kepentingan jangka pendek tanpa memikirkan akibatnya pada jangka panjang.Dugaan sementara berkurangnya luas kawasan hutan di Desa Suka Makmur Kecamatan Kutalimbaru dan Desa Kuta Rayat Kecamatan Namanteran adalah akibat adanya aktivitas pembalakan liar yang dilakukan masyarakat.

Untuk mengetahui faktor penyebab, intensitas, dan tanggapan masyarakat tentang permasalahan pembalakan liar yang terjadi pada 3 Desa yaitu Desa Suka Makmur Kecamatan Kutalimbaru dan Desa Kuta Rayat dan Desa Kuta Gugung Kecamatan Namanteran maka perlu dilakukan penelitian.

\section{METODE PENELITIAN}

\section{Tempat dan Waktu Penelitian}

Tempat penelitian mencakup 3 (tiga) desa yang terletak di 2 (dua) Kecamatan, yaitu Desa Kuta Rayat dan Desa Kuta Gugung yang terletak di Kecamatan Namanteran dan Desa Suka Makmur di Kecamatan Kutalimbaru, dimana ketiga desa tersebut merupakan bagian dari Kabupaten Tanah Karo Provinsi Sumatera Utara. Penelitian ini dilaksanakan dari bulan November 2019 sampai Januari 2020.

\section{Alat dan Bahan Penelitian}

Alat dan bahan yang digunakan dalam penelitian ini adalah alat tulis, kamera dan angket/kuisioner.

\section{Teknik Pengambilan Data}

Pengambilan data dilakukan dengan cara menjalankan kuisioner dan studi pustaka.

Populasi dan Sampel

Data yang diperoleh dari 3 desa, yaitu Desa Kuta Rayat dan Desa Suka Makmur dan Desa Kuta Gugung. Pengamatan pada areal kawasan desa tersebut dilakukan dengan Metode purposive sampling yaitu masyarakat yang terlibat dalam aktivitas pembalakan liar melalui wawancara dengan 73 responden dari seluruh desa dengan menggunakan daftar kuisioner, dengan rincian sebagai berikut: Berdasarkan data statistik tiap desa maka diketahui jumlah Kepala Keluarga per Desa adalah sebagai berikut: Desa Kuta Rayat: 666 KK, Desa Kuta Gugung: 325 KK, dan Desa Suka Makmur: 65 KK. Dalam penelitian ini sampel yang digunakan berkisar antara 5-15\% dengan rincian: Desa Kuta Rayat: 43 sampel, Desa Kuta Gugung: 17 sampel, dan Desa Suka Makmur: 13 sampel. Dengan total jumlah responden adalah 73 Jiwa dari seluruh desa.

Kuisioner

Kuisioner berisikan sekumpulan pertanyaan yang di tujukan kepada reponden dalam penelitian.

a. Karakteristik responden adalah tingkat Pendidikan, pekerjaan dan umur, 
b. Sejumlah pertanyaan yang berkaitan dengan Faktor Penyebab Pembalakan Liar.

\section{METODE PENGOLAHAN DATA}

Penelitian ini dilakukan dengan metode purposivesampling dimana desa sampel adalah desa yang bersinggungan langsung dan desa yang tidak bersinggungan langsung dengan aktivitas pembalakan liar.Pengumpulan data primer dengan teknik wawancara terstruktur di lokasi penelitian untuk mengetahui validitas dan realibilitas. Data yang diperoleh dianalisis dengan menggunakan metode deskriptif.

\section{HASIL DAN PEMBAHASAN}

\section{Karakteristik Responden}

Responden yang telah diwawancarai untuk skripsi ini berjumlah 73 orang, yang terdiri dari 43 responden di desa Kuta Rayat, 17 responden di desa Kuta Gugung dan 13 responden di desa Suka Makmur. Secara umum responden yang telah diwawancarai adalah 41 laki-laki dan 32 perempuan. Rata-rata umur responden secara keseluruhan adalah 43,25 tahun yang tersebar pada rentang 24 tahun hingga 77 tahun. Distribusi responden berdasarkan tingkat umur dan jenis kelamin responden dapat dilihat pada (Tabel 1) di bawah ini.

Tabel 1. Karakteristik responden berdasarkan umur dan jenis kelamin

\begin{tabular}{llllll}
\hline \multirow{2}{*}{ No } & Desa & Kemukiman & Jumlah & Rata-RataUmur \\
\cline { 3 - 5 } & & Laki-Laki & Perempuan & Responden \\
\hline $\mathbf{1}$ & Kuta Rayat & Kuta rayat & 25 & 18 & 46,30 \\
$\mathbf{2}$ & KutaGugung & Kuta Gugung & 9 & 8 & 41,05 \\
$\mathbf{3}$ & SukaMakmur & Suka Makmur & 8 & 5 & 42,41 \\
\hline \multicolumn{2}{l}{ Total } & & 42 & 31 & \\
\hline
\end{tabular}

Mayoritas responden (18 orang) tamat SD, 23orang tamat SMP, 21 orang tamat SMA, dan 11 orang tamat perguruan tinggi (Tabel 2). 
Tabel 2. Tingkat pendidikan responden di masing-masing Desa

\begin{tabular}{|c|c|c|c|c|c|}
\hline \multirow[t]{2}{*}{ NO } & \multirow[t]{2}{*}{ DESA } & \multicolumn{4}{|c|}{ PENDIDIKAN } \\
\hline & & SD & $\begin{array}{l}\text { SM } \\
\text { P }\end{array}$ & SMA & PT \\
\hline 1. & Kuta Rayat & 16 & 9 & 13 & 5 \\
\hline 2. & $\begin{array}{l}\text { Suka } \\
\text { Makmur }\end{array}$ & - & 4 & 5 & 4 \\
\hline 3. & $\begin{array}{l}\text { Kuta } \\
\text { Gugung }\end{array}$ & 2 & 10 & 3 & 2 \\
\hline \multicolumn{2}{|c|}{ Total } & 18 & 23 & 21 & 11 \\
\hline
\end{tabular}

Seluruh responden yang diwawancarai bermatapencaharian sebagai petani, pedagang, PNS bahkan ada juga yang hanya ibu rumah tangga (Tabel 3).

Tabel 3. Tingkat pekerjaan responden di masing-masing Desa

\begin{tabular}{|c|l|l|l|l|l|}
\hline \multirow{2}{*}{ NO } & \multirow{2}{*}{ DESA } & \multicolumn{3}{|c|}{ PEKERJAAN } \\
\cline { 3 - 6 } & & PETANI & PNS & PEDAGANG & IRT \\
\hline 1. & Kuta Rayat & 30 & 4 & 8 & 1 \\
\hline 2. & $\begin{array}{l}\text { Suka } \\
\text { Makmur }\end{array}$ & 10 & - & 3 & - \\
\hline 3. & $\begin{array}{l}\text { Kuta } \\
\text { Gugung }\end{array}$ & 8 & 2 & 7 & - \\
\hline \multicolumn{2}{|c|}{ Total } & 48 & 6 & 18 & 1 \\
\hline
\end{tabular}

\section{Faktor Pembalakan Liar}

Penyebab pembalakan liar di ketiga desa tersebut diakibatkan dari beberapa faktor yang terdapat dari hasil wawancara yang dilakukan dalam penelitian kepada masyarakat desa. Dari hasil wawancara diketiga desa tersebut dapat disimpulkan bahwa terdapat beberapa faktor penyebab pembalakan liar, antara lain: faktor ekonomi, faktor pendidikan, dan faktor keterbatasan pengawas hutan.

\subsubsection{Faktor Ekonomi}

Salah satu faktor untuk mengetahui keadaan ekonomi masyarakat ketiga desa tempat penelitian adalah pendapatan masyarakat desa. Adapun hasil data pendapatan masyarakat di setiap desa tersebut dapat dilihat berdasarkan tabel di bawah ini:

Tabel 4. Pendapatan rata-rata masyarakat 


\begin{tabular}{|l|l|l|}
\hline No. & Keterangan & Jumlah Rata-Rata (Rp) \\
\hline 1. & Pendapatan desa Kuta Rayat per bulan & $1.450 .000,00$ \\
\hline 2. & Pendapatan desa Kuta Gugung per tahun & $1.500 .000,00$ \\
\hline 3. & Pendapatan dusun Suka Makmur per bulan & $1.300 .000,00$ \\
\hline
\end{tabular}

Pada Tabel 4 diatas menunjukkan bahwa tingkat pendapatan masyarakat di ketiga desa tersebut masih tergolong rendah dan lebih kecil bila dibandingkan dari nilai UMR Kabupaten Karo tahun 2019 sebesar Rp 2.829.558,- (www.sumutinvest.com). Hal itu yang membuat masyarakat melakukan pembalakan liar untuk memenuhi kebutuhan hidupnya tanpa memikirkan dampak yang terjadi untuk kedepannya. Selain mendapatkan kayu yang bisa dijual, pembalakan yang dilakukan masyarakat juga mengakibatkan terbukanya lahan pertanian baru bagi masyarakat desa.

\subsubsection{Faktor Pendidikan}

Aspek pendidikan menjadi salah satu penyebab aktivitas pembalakan liar.Pendidikan yang rendah dari masing-masing penduduk di ketiga desa tersebut membuat masyarakat melakukan kegiatan pembalakan liar.Dari data di atas didapatkan bahwa persentase pendidikanresponden dari ketiga desa tersebut adalah pendidikan masyarakat desa Kuta Rayat tamatan Sekolah Dasar (SD), pendidikan masyarakat desa Kuta Gugung tamatan Sekolah Menengah Atas (SMA), dan pendidikan masyarakat desa Suka Makmur tamatan Sekolah Menengah Pertama (SMP). Rendahnya pendidikan masyarakat dari ketiga desa tersebut membuat kurangnya peluang pekerjaan yang didapatkan masyarakat serta membuat pola fikirmasyarakat tentang pentingnya hutan dan fungsi hutan tersebut menjadi rendah.Hal ini membuat masyarakat melakukan pembalakan liar sehingga merusak ekosistem hutan.

\subsubsection{Faktor Keterbatasan Petugas Pengawas Hutan}

Basuki, at all (2013) meneliti salah satu faktor utama penyebab maraknya praktek pembalakan liar adalah tidak efektifnya pengawasan hutan dan pengendalian penatauusahaan kayu dalam mencegah terjadinya praktek pembalakan liar. Dari hasil wawancara di ketiga desa tersebut terdapat lahan yang subur namun ekonomi masyarakatnya rendah, sebagian besar masyarakatnya pun berpendidikan rendah serta kurangnya pengawasan petugas hutan membuat aktivitas pembalakan liar kian marak terjadi.

Dalam penelitian ini pembalakan liar di tiga desa disebabkan oleh: (1) faktor ekonomi masyarakat desa yang rendah dimana pendapatan masyarakat desa lebih kecil dari Upah Minimum Kabupaten Karo, (2) faktor pendidikan masyarakat desa yang rata-rata 
merupakan lulusan Sekolah Dasar (SD), (3) faktor kesuburan alam yang menyebabkan lahan tepat dijadikan sebagai lahan pertanian, dan (4) faktor pengawasan hutan yang rendah. Keseluruhan faktor inilah yang membuat tinggi nya intensitas pembalakan liar yang terjadi di ketiga desa tersebut, walaupun desa Kuta Gugung Kecamatan Namanteran lebih rendah intensitas nya dibanding desa Kuta Rayat Kecamatan Namanteran dan desa Suka Makmur Kecamatan Kutalimbaru.

Hal lain yang menjadi permasalahan dalam penelitian terkait pembalakan liar ini adalah persepsi masyarakat di ketiga desa. Masyarakat memandang bahwa melakukan pembalakan liar merupakan hal yang lumrah terjadi karena keterbatasan lahan pertanian yang mereka miliki. Kurangnya sosialisasi dari petugas mengenai peraturan penggunaan kawasan hutan membuat masyarakat masih belum mengetahui bahwa tindakan pembalakan liar merupakan tindakan yang tidak tepat dilakukan.

Bahwa adanya ketegasan dari pemerintah untuk menanggulangi masalah pembalakan liar adalah dengan memberikan solusi kepada masyarakat desa. Diantara beberapa solusi yang dapat diberikan pemerintah adalah: (1) mendirikan kawasan lindung, (2) memberikan pendidikan kepada masyarakat tentang perlindungan hgutan, (3) memebrikan atau menyediakan lahan pertanian kepada masyarakat, (4) memberikan penyuluhan dan pelatihan kewirausahaan kepada masyarakat agar masyarakat memiliki mata pencaharian selain pertanian. Selain itu pemerintah juga semestinya memberikan motivasi kepada masyarakat untuk ikut betanggungjawab terhadap kerusakan hutan yang telah dilakukan. Pemerintah desa dapat mengajak masyarakat melakukan tindakan seperti reboisasi atau penanaman hutan kembali di wilayah hutan rakyat, tidak membuang sampah sembarangan, memanfaatkan sumber daya alam selain kayu dan sebagainnya. Melalui pendekatan ini, pihak berwajib juga ingin lebih mengenal dan lebih dekat dengan masyarakat di wilayah tugasnya. Hal tersebut dilakukan untuk melindungi semua pihak terutama masyarakat sekitar dari ancaman bahaya yang dapat ditimbulkan oleh kerusakan lahan hutan.

\section{SIMPULAN DAN SARAN}

Faktor yang mempengaruhi aktivitas pembalakan liar di kawasan Taman Hutan Raya Bukit Barisan diantaranya faktor ekonomi, faktor pendidikan, faktor kesuburan tanah dan faktor keterbatasan pengawas hutan. Hasil data yang diperoleh dari penelitian di ketiga desa ( Desa Kuta Rayat, Desa Kuta Gugung dan Desa Suka Makmur) menunjukkan bahwa masyarakat desa memiliki penghasilan yang rendah, pendidikan yang rendah, tanah yang subur dan pengawasan dari polisi hutan yang kurang maksimal mengakibatkan masyarakat masih melakukan aktivitas pembalakan liar di kawasan Taman Hutan Raya Bukit Barisan. Upaya mencegah pembalakan liar di kawasan hutan lindung tersebut diperlukan kebijakan pemerintah Kabupaten Karo Provinsi Sumatera Utara untuk dapat membantu masyarakat yang sudah kehilangan harta benda mereka akibat bencana Gunung Api Sinabung berupa penyediaan aktivitas ekonomi dan lapangan pekerjaan untuk meningkatkan kebutuhan 
hidup masyarakat tersebut. Serta peningkatan pengawasan dari pihak Taman Hutan Raya Bukit Barisan guna menjaga agar penebangan liar tidak semakin luas. Oleh karena itu, perlunya koordinasi Dinas Kehutanan Provinsi Sumatera Utara dengan Dinas yang terkait lainnya sehingga mampu meningkatkan pendapatan masyarakat di sekitar hutan lindung.

\section{DAFTAR PUSTAKA}

Deni Susilawati, 2008. tentang Analisis Dampak dan Faktor yang Mempengaruhi Perambahan Hutan.

Selly, S. 2011. Tentang Faktor yang Mempengaruhi Masyarakat Menggarap Lahan di Hutan Lindung: Studi Kasus di Kabupaten Garut Jawa Barat.

Undang- Undang Nomor 5 tahun 1990, tentang Konservasi Keanekaragaman Hayati dan Ekosistemnya. 